\title{
APPLYING MEANS-END CHAIN THEORY AND LADDERING INTERVIEWS TO THE STUDY OF PRODUCT ATTRIBUTES FOR DALAT POTATOES
}

\author{
LE THI THANH XUAN \\ Ho Chi Minh City University of Technology, Vietnam National University HCMC \\ lttxuan@hcmut.edu.vn \\ NGUYEN HAN VU \\ Ho Chi Minh City University of Technology, Vietnam National University HCMC \\ nhvu@hcmut.edu.vn
}

(Received: August 16, 2017; Revised: August 29, 2017; Accepted: October 31,2017)

\begin{abstract}
Dalat potato brand has currently been facing unfair competition from wholesalers using Chinese potatoes labelled with Vietnamese brand to disguise their true origin. Accordingly, potatoes from China are first transported to Lam Dong and then covered by Lam Dong soil to cheat consumers. This study, therefore, aims to explore key attributes of Dalat potatoes, and the benefits and values created by these attributes for consumers of Dalat potatoes. In order to address the research objective, the study uses qualitative approach based on means-end chain theory and laddering interviews to collect and analyse the data. Eventually, the linkage between attributes, consequences and values are established to help governmental authorities of Lam Dong province to develop strategies for promoting Dalat potato brand. The finding shows that 'High food value', 'Trustful product' and 'Tasty and greasy taste' are key attributes of Dalat potatoes. The linkage between potatoes attributes, benefits and values show that consuming good farm produce like Dalat potatoes help consumers enjoy a better life. This is essential for authorities to position and build a more solid brand for this specialty. To conclude, the paper discusses some managerial implications for promoting and branding Dalat potatoes.
\end{abstract}

Keywords: Attributes-benefits-values; Dalat potato; Laddering interview; Means-end chain theory.

\section{Introduction}

A deeper integration into global economy creates both opportunities and challenges for many industries, especially when Vietnam is an agriculture country with various farm produce. It is important for businesses to position their products to survive and develop in a huge competitive market. This product positioning process helps businesses identify their strengths and drawbacks to develop suitable marketing strategies.

Dalat potato is one of typical specialties of Lam Dong province. Unfortunately, Chinese potato is now disguised as Dalat potato to cheat customers (Dũng, 2015). According to Mr. Nguyen Van Son, Director of Agriculture and Rural Development of the province, even though governmental authorities of Lam Dong province and his department have made great efforts to build up and promote Dalat potato brand since 2013, the situation has not changed much and this product has been facing a huge threat from such an unfair competition. Therefore, in the context of Chinese food invasion, Dalat potato positioning is crucial to build an effective branding campaign and strengthening brand differentiation from China potato. These activities will have to attract customers' attention, provide them with comprehensive information and simplify decision-making process for customers (Ries 
and Trout, 1986 cited in Jeng \& Yeh, 2016). In recent years, under the unsafe food market due to the attack of Chinese dirty foods and goods, Vietnamese people are increasing their awareness of safe foods and using local products. Previous studies point out that customers nowadays are willing to pay more for green and safe products (Schubert, Kandampully, Solnet, \& Kralj, 2010). These are reasons why it is necessary, not only for scholars but also for Lam Dong governmental authorities, to explore and use the attributes of Dalat potato to communicate with customers and help them to choose Vietnamese safe foods more easily.

In practice, the process of purchasing is affected not only by customers' knowledge of the product but also their personal characteristics (Barrena \& Sánchez, 2009). Consumers' personalities are crucial for them to determine how products enhance their lifevalue and which product attributes affect consumer purchase decision. In addition, food safety is always an important issue. Therefore, customer always wants to know the real attributes of products they buy; and they pay a high attention to benefits and values that products can bring to them (Barrena \& Sánchez, 2009).

For the above reasons, this study employs a combined method of a means-end chain (MEC) theory and laddering interviews to investigate Dalat potato attributes from customers' perspectives, the value decisionmaking process of customers and explain how to link values to customers during brand positioning (Jeng \& Yeh, 2016) and their personalities in choosing a product (Barrena \& Sánchez, 2009). MEC theory and laddering interviews are used as a qualitative approach to (1) identify attributes of Dalat potato; (2) explore how these attributes create consequences in consuming Dalat potato; and (3) examine the effect of these attributes and consumer values on information processing and decision-making outcomes and to establish the linkages between attributes, consequences, and values. The finding will help governmental authorities of Lam Dong province develop strategies to build and promote Dalat potato brand.

\section{Literature review}

\subsection{Product attributes}

There are three attributes of a brand including product attributes, benefit attributes, and situation-based attributes (Romaniuk, 2003). Product attributes are something that a customer really wants and is actually buying. They are product features that provide the desired benefits which may make customers satisfy. If customers cannot know what they are offered by a brand or product, they are reluctant to or even never choose and decide to purchase. Furthermore, product category will have impacts on customers' recall of a brand (Alba and Chattopadhyay 1986, cited in Romaniuk, 2003). Many scholars argued that product attributes embody a vector of characteristics which can be measured (Zhu, Wang, Yan, \& Wu, 2009). Improtantly, these characteristics have a significant link with consumers' functional or hedonic needs, which are related to necessities and luxuries, respectively. In their study, Thompson, Halmiton and Rust (2005, cited in Zhu et al., 2009, p. 298) stated that "for some consumers, having additional features enables them to extract greater utility from the product and hence greater satisfaction; for some others, additional features may be undesirable, unusable and hence a waste of time and money".

\subsection{Customer values}

From the literature, there are some definitions of customer values in several very different contexts. In his study, Woodruff (1997, p. 142) defines customer value as " $a$ customer's perceived preference for and evaluation of those product attributes, attributes performances, and consequences 
arising from use that facilitate (or block) achieving he customer's goal an purposes in use situations.". Customer values is important to customer satisfaction, the way in which customers response to evaluation when they consume a product. Understanding this concept clearly will help managers decide how to create and implement strategies on key attribute-based buying criteria (Woodruff, 1997).

\subsection{Means-end chain (MEC) theory}

The MEC theory of consumer behaviors is a framework for understanding the associations that groups of consumers make between products' attributes and more personally relevant and abstract consequences and values (Leppard, Russell, \& Cox, 2004). In the MEC, there are six levels including three lower levels - concrete attributes, abstract attributes and functional attributes and three upper levels - psychosocial consequences, instrumental values and terminal values (Barrena \& Sánchez, 2009). Generally, an attribute of a product plays an important role in the moment it makes customers think it creates expected or unexpected consequences, which then become personal values for them (Barrena \& Sánchez, 2009). There are two assumptions in this framework (Costa, Dekker, \& Jongen, 2004). The first is, based on consumers' evaluation of self-relevant consequences; they buy and use products/services. The attributes of products are inferred to establish these selfrelevant consequences based on individually held values. The attributes of products, the consequences, the values and the links between them create MEC. The second is about the level of intent and awareness of consumption-related behavioral decisions. Customers are free to decide which products to choose to take positive consequences and avoid negative outcomes (Olson, Renolds, \& Partners, 2001). The MEC is used to evaluate the extent to which its users feel they have achieved a better understanding of consumers' decision-making processes (Costa et al., 2004). The basic MEC model includes three levels of customers' knowledge: attributes, consequences, and values.

\subsection{Laddering interview technique}

In their paper, Olson et al. (2001) use laddering interviews as the methodology to identify attributes-consequences-values in MEC theory. Laddering is about one-on-one interview which is structured and focused on the question "Why do you ...?" and "Why is that important to you?" repeatedly. The purpose of these questions is to determine sets of linkages between attributes (A), consequences (C) and values (V) (Reynolds \& Gutman, 1988). These linkages serve to distinguish products in the same categories.

There are two types of laddering interviews namely soft laddering and hard laddering (Grunert \& Grunert, 1995; Jeng \& Yeh, 2016). Soft laddering is conducted by using in-depth interviews with open questions, and not suitable for collecting a large sample (Hofstede et al 1998, cited in Jeng \& Yeh, 2016). This approach gives respondents a freedom to give unrestricted answer. Hard laddering can be conducted by phones, emails, or self-administrated questionnaires to collect data. This approach requires a large sample size (Hofstede at al. 1998, cited in Jeng \& Yeh, 2016).

Three steps are performed in laddering interview technique. Firstly, major attributes of different products are identified and compared. Secondly, attributes of product and the relationship between consequences and consumer values are explained in detail by respondents. The linkage of attributes, consequences, and values is uncovered until the respondents can no longer give answers. Lastly, association between A-C-V is uncovered and hierarchical value map (HVM) is developed (Jeng \& Yeh, 2016; Kang, Kang, Yoon, \& Kim, 2014; Leppard et al., 2004; 
Reynolds \& Gutman, 1988).

\section{Methodology}

This study aims to (1) identify attributes of Dalat potato; (2) explore how these attributes create consequences in consuming Dalat potato; and (3) examine the effect of these attributes and consumer values on information processing and decision-making outcomes and to establish the linkages between attributes, consequences, and values. A qualitative approach is employed to address these purposes. Dalat is a famous tourist destination attracting people from across the country. Therefore, Dalat market is chosen as the setting for this study. Not only Lam Dong residents but travelers also buy Dalat potato and other specialties in supermarkets and "Chợ Đà Lạt" to consume or to give others as gifts from their trip.

The study uses soft-laddering interview to collect data with 3 stages (Barrena \& Sánchez, 2009). In the first stage, different techniques are used to identify relevant attributes of Dalat potatoes. Two experts in potato and three potato farmers were interviewed to initially explore and frame the understanding of potato characteristics. In the second stage, softladdering interviews are used to collect data and twenty potato buyers and consumers at markets or supermarkets are approached and interviewed with a series of questions such as "Why is that important to you?". The purpose of this stage is to let respondents explain why attributes chosen in the first stage can be used to link to their associated consequences and values. In the last stage, based on an implication matrix formed by links of attributes-consequences-values, a hierarchical value map (HVM) is constructed.

As mentioned in the literature, softladdering let respondents talk freely in the interview, and the attribute-consequencevalue linkage have to be reconstructed afterwards (Barrena \& Sánchez, 2009). To filter appropriate respondents and to explore
Dalat potato attributes, each interview includes the following open questions:

- Do you usually consume Dalat potato?

- For what purpose do you use Dalat potato?

- In your opinion, which attributes of Dalat potatoes are important?

- Why these attributes are important to you? Or Why do you think these attributes are important?

- Except attributes you have just mentioned, which other attributes of Dalat potatoes are also important?

To explore the relationship between attributes, consequences and values that Dalat potatoes provide to consumers, the following questions are used:

- In your opinion, which benefits do the attributes $\mathrm{ABC}$ you have just mentioned bring you?

- In your opinion, which values do the benefits you have just mentioned bring you or your health?

Open-ended interviews are used to explore, from consumers' point of views, how attributes lead to benefits/consequences, and how benefits/consequences lead to values. The interview continued until consumers can no longer list any values of Dalat potatoes. Data collected is then analyzed using the following steps (Reynolds and Gutman, 1988):

- Interview-content analysis to describe attributes, consequences - value of Dalat potatoes: this is to identify attributesconsequences and values from all respondents' opinions.

- Developing the implication matrix: in this step, the matrix is used to display the number of times each element leads to each other element.

- Constructing the Hierarchical Value Map (HVM): to construct this HVM, the chain to reflect the relation between attributesconsequences-values which have to be 
reconstructed from the aggregate data. The term "chains" will be used in reference to sequences of elements which emerge from the aggregate implication matrix.

- Determining dominant perceptual orientations is about considering any pathway from bottom to top as a potential chain representing a perceptual orientation.

\section{Research findings \\ 4.1. Identifying Attributes - Consequences - Values}

Interviewing potato experts and farmers give a direction for interviewing consumers. In this stage, there are six (06) attributes of Dalat potatoes including: tasty and greasy potato's taste (after cooking), thin skin, fresh potato without preservative substance, high food value, good shape after cooking, low level of pesticide, which are all agreed by interviewees. There are three (03) attributes of Dalat potatoes pointed out by potato experts and agreed by two out of three interviewed farmers, namely: uneven and medium size, a few of spots, and white or light yellow flesh after cooking. Totally, all nine (09) attributes are used as the basis for interviewing consumers. In the second stage, potato consumers are interviewed to explore attributes (A), consequences (C) and value (V). MEC theory is employed to analyse these elements. According to Reynolds \& Gutman (1988), elements should not be coded individually but in group to assure the meaning and the relationship between A-C-V in the HVM. The coded elements are shown in Table 1 below.

\section{Table 1}

Elements in Attributes-Consequences-Values of Dalat potatoes

\begin{tabular}{|c|c|c|}
\hline & ATTRIBUTES-CONSEQUENCES-VALUES & Frequencies \\
\hline \multicolumn{3}{|c|}{ VALUES: } \\
\hline $\mathrm{V} 1$ & Pleased and satisfied when using & 19 \\
\hline $\mathrm{V} 2$ & Increasing the family happiness (family attachment) & 18 \\
\hline V3 & Increasing life quality (food safety) & 20 \\
\hline V4 & Increasing self-esteem (being confident in ability of choosing food) & 18 \\
\hline \multicolumn{3}{|c|}{ CONSEQUENCES: } \\
\hline & \multicolumn{2}{|l|}{ Functional consequences: } \\
\hline $\mathrm{C} 1$ & Economical & 2 \\
\hline $\mathrm{C} 2$ & Easy and quick to cook & 7 \\
\hline $\mathrm{C} 3$ & Time saving & 5 \\
\hline $\mathrm{C} 4$ & Good for health & 18 \\
\hline C5 & Good for beauty & 4 \\
\hline \multirow[t]{2}{*}{ C6 } & Preserving in long time & 5 \\
\hline & \multicolumn{2}{|l|}{ Psychological consequences: } \\
\hline $\mathrm{C} 7$ & Delicious & 9 \\
\hline
\end{tabular}




\begin{tabular}{|l|l|c|}
\hline \multicolumn{1}{|c|}{ ATTRIBUTES-CONSEQUENCES-VALUES } & Frequencies \\
\hline C8 & Nice to decorate & 8 \\
\hline C9 & Pleased as high quality food consuming & 14 \\
\hline C10 & No harm to health & 7 \\
\hline C11 & Close and friendly to consumer & 2 \\
\hline & \multicolumn{1}{|c|}{ ATRIBUTES } & 10 \\
\hline & Concrete attributes & 6 \\
\hline A1 & Tasty and greasy taste (after cooking) & 1 \\
\hline A2 & Thin skin & 4 \\
\hline A3 & Uneven and medium size & 5 \\
\hline A4 & A few of small spots & 7 \\
\hline A5 & No changed or light-yellow color of flesh after cooking & 19 \\
\hline A6 & Fresh potatoes & 4 \\
\hline A7 & More expensive price (as compared with other types of potatoes) & 2 \\
\hline A8 & High food value & 10 \\
\hline A9 & Good shape after cooking & \\
\hline & Abstract attributes: & \\
\hline A10 & Natural product (not processed) & \\
\hline A11 & Familiar and traditional food & \\
\hline A12 & Trustful product (without preservative substance) & \\
\hline
\end{tabular}

\subsection{Developing the implication matrix}

The implication matrix is used to HVM as an important tool to count the frequencies of connections. The attributes - consequences - values connection identified by laddering interview is presented by numbers in the matrix. These numbers represent the number of counts from the interviews. The larger the number is counted, the stronger the connection is. There are two types of connections: direct connections presenting the relations between adjacent elements and indirect connections presenting ones not adjacent but via other element. The number before the semi-colon (;) is for direct connections, and the one after it is for indirect connections. Table 2 below shows the implication matrix of Dalat potatoes. 


\section{Table 2}

The implication matrix of Dalat potatoes

\begin{tabular}{|c|c|c|c|c|c|c|c|c|c|c|c|c|c|c|c|c|}
\hline & C1 & $\mathrm{C} 2$ & $\mathrm{C3}$ & $\mathrm{C} 4$ & C5 & C6 & C7 & C8 & C9 & C10 & C11 & V1 & $\mathrm{V} 2$ & V3 & V4 & Total \\
\hline A1 & & & & & & & $8 ; 0$ & & $2 ; 1$ & & & $0 ; 4$ & $0 ; 3$ & $0 ; 1$ & $0 ; 1$ & $10 ; 10$ \\
\hline A2 & & $4 ; 0$ & $2 ; 2$ & & & & & & & & & $0 ; 2$ & $0 ; 1$ & & & $6 ; 5$ \\
\hline A3 & & & & & & & & $1 ; 0$ & & & & & $0 ; 1$ & & & $1 ; 1$ \\
\hline A4 & & $3 ; 0$ & $0 ; 2$ & & & & & $1 ; 0$ & & & & $0 ; 1$ & & & & $4 ; 3$ \\
\hline A5 & & & & & & & $1 ; 0$ & $2 ; 0$ & $2 ; 2$ & & & $0 ; 1$ & $0 ; 1$ & & & $5 ; 4$ \\
\hline A6 & & & & & $1 ; 0$ & $2 ; 0$ & & & $3 ; 1$ & $1 ; 0$ & & $0 ; 1$ & $0 ; 1$ & $0 ; 1$ & $0 ; 1$ & $7 ; 5$ \\
\hline A7 & $1 ; 0$ & & & & & & & & & & & & & & $0 ; 2$ & $1 ; 2$ \\
\hline A8 & & & & $18 ; 1$ & $1 ; 1$ & & & & $0 ; 5$ & $0 ; 2$ & & $0 ; 2$ & $0 ; 1$ & $0 ; 2$ & $0 ; 2$ & $19 ; 16$ \\
\hline A9 & & & $0 ; 1$ & & & & & $4 ; 0$ & $0 ; 1$ & & & $0 ; 1$ & $0 ; 1$ & & $0 ; 2$ & $4 ; 6$ \\
\hline A10 & & & & & $2 ; 1$ & $1 ; 0$ & & & $2 ; 1$ & & & & & $0 ; 2$ & & $5 ; 4$ \\
\hline A11 & & & & & & & & & & & $2 ; 0$ & & $0 ; 2$ & & & $2 ; 2$ \\
\hline A12 & & & & & & $2 ; 0$ & & & $5 ; 2$ & $3 ; 2$ & & & & $0 ; 2$ & $0 ; 3$ & $10 ; 9$ \\
\hline C1 & & & & & & & & & & & & & $2 ; 0$ & & & $2 ; 0$ \\
\hline $\mathrm{C} 2$ & & & $3 ; 0$ & & & & & & & & & $2 ; 0$ & $1 ; 1$ & $0 ; 2$ & $1 ; 1$ & $7 ; 4$ \\
\hline C3 & & & & & & & & & & & & & $2 ; 0$ & $3 ; 0$ & & $5 ; 0$ \\
\hline $\mathrm{C} 4$ & & & & & & & & & & $3 ; 0$ & & $4 ; 0$ & $3 ; 0$ & $6 ; 0$ & $2 ; 2$ & $18 ; 2$ \\
\hline C5 & & & & & & & & & & & & $2 ; 0$ & & & $2 ; 0$ & $4 ; 0$ \\
\hline C6 & $1 ; 0$ & & & & & & & & & & & $1 ; 0$ & $2 ; 2$ & & $2 ; 1$ & $5 ; 3$ \\
\hline C7 & & & & & & & & & & & & $3 ; 0$ & $2 ; 0$ & $1 ; 0$ & $3 ; 2$ & $9 ; 2$ \\
\hline C8 & & & & & & & & & & & & $2 ; 0$ & $2 ; 0$ & & $4 ; 1$ & $8 ; 1$ \\
\hline C9 & & & & & & & & & & & & $3 ; 0$ & $2 ; 0$ & $7 ; 1$ & $2 ; 1$ & $14 ; 2$ \\
\hline C10 & & & & & & & & & & & & $2 ; 0$ & $2 ; 1$ & $3 ; 2$ & & $7 ; 3$ \\
\hline C11 & & & & & & & & & & & & & & & $2 ; 0$ & $2 ; 0$ \\
\hline Total & $2 ; 0$ & 7;0 & $5 ; 5$ & $18 ; 1$ & $4 ; 2$ & $5 ; 0$ & $9 ; 0$ & $8 ; 0$ & $14 ; 13$ & $7 ; 4$ & $2 ; 0$ & $19 ; 12$ & $18 ; 15$ & $20 ; 13$ & $18 ; 19$ & $156 ; 84$ \\
\hline
\end{tabular}

\subsection{Constructing the HVM}

The construction of HVM should start from the adjacent connections between elements to the formation of a link. By connecting all links, HVM is formed by relationships in the implication matrix of elements (Table 2). As per the implication matrix above, there are some connections which are rarely mentioned by interviewees such as the connection between A3 (Uneven and medium size) and C8 (Nice to decorate) $(1 ; 0)$, that between A7 (More expensive price) and $\mathrm{C} 1$ (Economical) $(1 ; 0)$, or that between $\mathrm{C} 1$ (Economical) and V2 (Increasing the family happiness/family attachment) (2;0). To assure that the HVM reflects the critical connections between $\mathrm{A}-\mathrm{C}-\mathrm{V}$, the elements mentioned under 3 times are removed when forming the HVM (Reynolds \& Gutman, 1988).

Starting from A1 (Tasty and greasy taste), 
the connection between $\mathrm{A} 1$ and $\mathrm{C} 7$ (Delicious) is (8;0) (over 3); therefore the link A1-C7 is formed. From $\mathrm{C} 7$ line, there are two connections C7-V1 (3;0) and C7-V4 (Increasing self-esteem)
$(3 ; 2)$ meeting the requirements of more than 3 times of mentioning. Therefore, the A1-C7-V1 link and A1-C7-V4 link starting from A1 are formed (Figure 1)

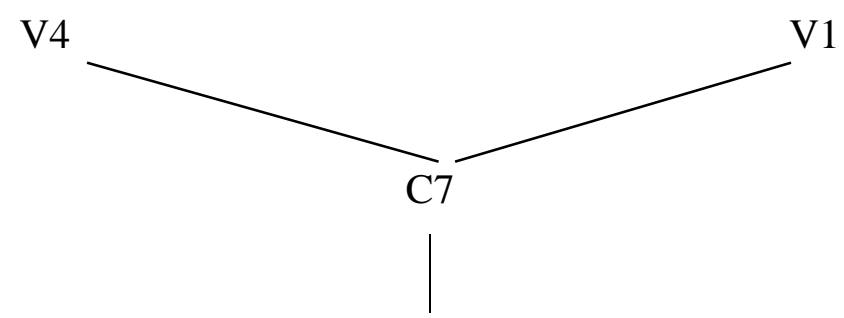

A1

Figure 1. Links from the attributes A1 (Tasty and greasy taste)

Similarly, all attributes from A2 to A12 are examined to determine their connections to consequences and values and the following HVM is constructed (Figure 2).
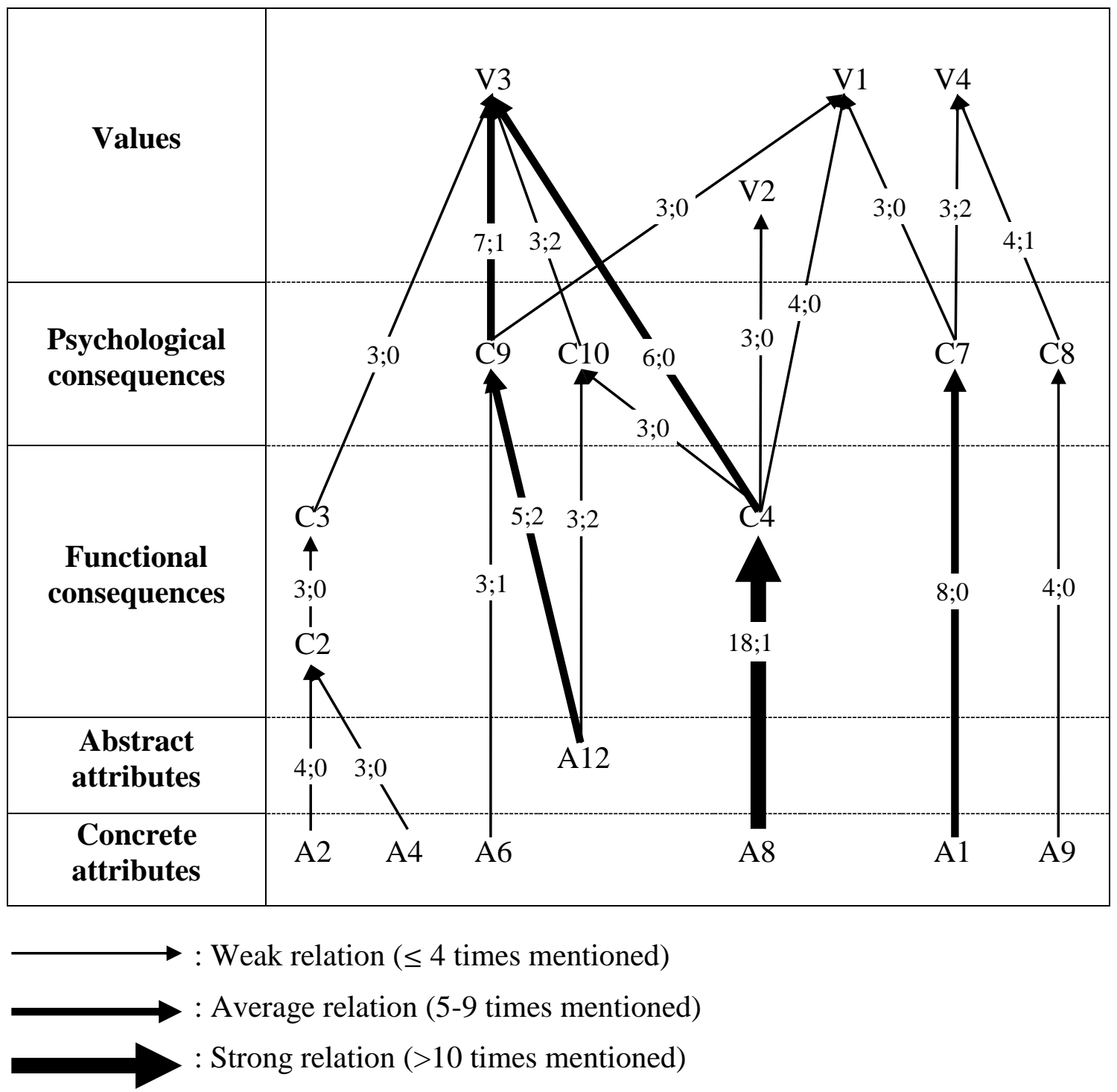

Figure 2. The HVM of Dalat potatoes(The cut-off level is 3) 
The HVM shows 93 per 156 times mentioning direct connections between elements (accounting for $60 \%$ ). According to previous studies (Fotopoulos, Krystallis, \& Ness, 2003), the relations in a link with the mentioned times under four (04), five to nine (5-9), and over ten (10) in the interviews are considered as weak, average and strong relation respectively. Based on that principle, it is clear that the relation between A8 (High food quality) and C4 (Good for health), which is mentioned 18 times, is the most strong relation $(18 ; 1)$. The average relations include A1-C7 (8;0), A12-C9 (5;2), C9-V3 (7;1), and C4-V3 (6;0).

The following table summarizes all elements in the HVM by a total number of relations (both direct and indirect). These relations include the ones to other elements (whether in or not in the HVM) and the ones from other elements (whether in or not in the HVM).

\section{Table 3}

Direct and indirect relations of elements in HVM

\begin{tabular}{|c|c|c|c|c|c|}
\hline Element & To & From & Element & To & From \\
\hline A1 & $10 ; 10$ & $00 ; 00$ & C4 & $18 ; 02$ & $18 ; 01$ \\
\hline A2 & $06 ; 05$ & $00 ; 00$ & C7 & $09 ; 02$ & $09 ; 00$ \\
\hline A4 & $04 ; 03$ & $00 ; 00$ & C8 & $08 ; 01$ & $08 ; 00$ \\
\hline A6 & $07 ; 05$ & $00 ; 00$ & C9 & $14 ; 02$ & $14 ; 13$ \\
\hline A8 & $19 ; 16$ & $00 ; 00$ & C10 & $07 ; 03$ & $07 ; 04$ \\
\hline A9 & $04 ; 06$ & $00 ; 00$ & V1 & $00 ; 00$ & $19 ; 12$ \\
\hline A12 & $10 ; 09$ & $00 ; 00$ & V2 & $00 ; 00$ & $18 ; 15$ \\
\hline C2 & $07 ; 04$ & $07 ; 00$ & V3 & $00 ; 00$ & $20 ; 13$ \\
\hline C3 & $05 ; 00$ & $05 ; 05$ & V4 & $00 ; 00$ & $18 ; 19$ \\
\hline
\end{tabular}

Table 3 shows V3 (Increasing life quality) as the most correlated element to others, and thus, the core value of Dalat potatoes when examining the $\mathrm{A}-\mathrm{C}-\mathrm{V}$ link. Other elements such as attribute A8 (High food quality) and consequence C4 (Good for health) also have close connections with other elements. When checking from the HVM (Figure 2), the link of $\mathrm{A} 8-\mathrm{C} 4-\mathrm{V} 3$ is most mentioned by interviewees, which is consistent with the result shown in Table 3.

\section{Conclusion}

\subsection{Research contribution}

The main objective of this study is to find out the attributes, benefits (consequences) and values when purchasing and consuming Dalat potatoes. These findings will not only help consumers to differentiate between Dalat potatoes and other types of potatoes but also provide relevant governmental agencies with important information about Dalat potatoes to promote the brand and keep consumers informed. The findings also help position Dalat potato brand in the market of agriculture produce. By combining the MEC and laddering interview technique to construct the HVM of Dalat potatoes, this study figures out significant attributes that help consumers purchase and consume Dalat potatoes. The finding shows that customers value the following attributes of Dalat potatoes: High food value (19), Trustful product (10), Tasty and greasy taste (10). Therefore, Department of Agriculture and Rural Development and 
other Lam Dong governmental authorities can focus on these strengths to build and promote a solid brand for Dalat potatoes. Regarding benefits when consuming potatoes; customers highly appreciate factors such as Good for health (18), Pleased as high quality food consuming (14), and Delicious (9). Hence, these values need to be highlighted in marketing strategies for Dalat potatoes. Particularly, in the context of widespread dirty foods now, consumers pay more attention to safe and clean food products. Finally, the study also points out the values that clients hope to achieve including Increasing life quality (food safety) (20), Pleased and satisfied when using (19), Increasing the family happiness (18) and Increasing selfesteem (18). This finding aims to provide consumers with more valuable information about this farm produce, create some expected values and satisfaction for them when consuming Dalat potatoes. The linkages between potatoes attributes, isbenefits and values show that consuming a good product like Dalat potatoes help to make a better life for consumers. This serves as a background for building and positioning Dalat potato brand for this specialty.

\subsection{Managerial implications}

Potato farmers and authorities of Lam Dong province find it hard to help consumers distinguish Dalat potatoes from other types of potatoes, especially those from China. Consumers are now confused with different kinds of potatoes and, more importantly, they do not have enough knowledge of and information about the potatoes they want to choose. Accordingly, several issues need to be discussed. Firstly, consumers should be aware of significant attributes of Dalat potatoes such as High food value, Trustful product, and Tasty and greasy taste. Moreover, they also need to know other attributes such as Thin skin, A few of small spots, Good shape after cooking, No changed or light-yellow color of flesh after cooking to distinguish Dalat potatoes from other types of potatoes. However, it seems they do not know much about these. Therefore, the message about Dalat potatoes should be sent to consumers through pictures or key words that impress on their mind. Moreover, the study shows that customers purchase Dalat potatoes because of the benefits and values brought about by the product. Hence, messages in advertisements should highlight the benefits and values of Dalat potatoes which consumers can get when consuming this product. Secondly, the research findings reveal that necessary information about the product need to be registered for Dalat potato brand. Agriculture and Rural Development Department of Lam Dong province needs to train potato farmers on technical process in growing potatoes and controlling the quality. In particular, Trustful product (without preservative substance) should be considered as important to Dalat potatoes. Potato farmers need governmental supports to standardize potato growing process and avoid using preservative substance or pesticides rashly.

\subsection{Limitations and further research}

However, the current study has some limitations. The first limitation is its small sample size, which means the number of interviewees approached is limited. Future research can avoid this limitation and reach a more generalized results by using ladderinginterview to collect questionnaire data but employing quantitative method to approach a larger number of interviewees. Secondly, all interviewees are living or working in Dalat and more or less have some experiences with Dalat potatoes. Thus, the research finding might not express the practical attributesbenefit-values of Dalat potatoes of customers from other provinces/cities. Further research should be conducted in key market segmentations like Hochiminh city to figure out customers' awareness of the attributes, benefits and values provided by Dalat potatoes 


\section{References}

Barrena, R., \& Sánchez, M. (2009). Consumption frequency and degree of abstraction: A study using the laddering technique on beef consumers. Food Quality and Preference, 20, 144-155.

Costa, A. I. A., Dekker, M., \& Jongen, W. M. F. (2004). An overview of means-end theory: potential application in consumer-oriented food product design. Trends in Food Science \& Technology, 15(7-8), 403-415. doi: http://dx.doi.org/10.1016/j.tifs.2004.02.005.

Dũng, Q. (2015, 21 Aug 2015). Khoai tây Trung Quốc đội lốt khoai tây Đà Lạt tăng giá gấp bốn. VnExpress. Retrieved from http://kinhdoanh.vnexpress.net/tin-tuc/hang-hoa/khoai-tay-trung-quoc-doi-lot-da-lat-tang-giagap-bon-3266937.html.

Fotopoulos, C., Krystallis, A., \& Ness, M. (2003). Wine produced by organic grapes in Greece: using means—end chains analysis to reveal organic buyers' purchasing motives in comparison to the non-buyers. Food Quality and Preference, 14(7), 549-566. doi: http://dx.doi.org/10.1016/S0950-3293(02)00130-1.

Grunert, K. G., \& Grunert, S. C. (1995). Measuring subjective meaning structures by the laddering method: Theoretical considerations and methodological problems. International Journal of Research in Marketing, 12(3), 209-225. doi: http://dx.doi.org/10.1016/0167-8116(95)00022-T.

Jeng, M.-Y., \& Yeh, T.-M. (2016). The effect of consumer values on the brand position of green restaurants by means-end chain and laddering interviews. Service Business, 10(1), 223-238. doi:10.1007/s11628-015-0266-1.

Kang, H., Kang, M., Yoon, S., \& Kim, D. (2014). A consumer value analysis of mobile internet protocol television based on a means-end chain theory. Service Business, 8(4), 587-613. doi:10.1007/s11628-013-0208-8

Leppard, P., Russell, C. G., \& Cox, D. N. (2004). Improving means-end-chain studies by using a ranking method to construct hierarchical value maps. Food Quality and Preference, 15(5), 489-497. doi: http://dx.doi.org/10.1016/j.foodqual.2003.09.001.

Olson, J. C., Renolds, T. J., \& Partners, R. (2001). The means-end approach to understanding consumer decisionmaking. In T. J. Reynolds \& J. C. Olson (Eds.), Understanding consumer decision-making: The Means-end approach to marketing and advertising strategy (pp. 3-20): Mahwah, N.J.: Psychology Press. 2000.

Reynolds, T. J., \& Gutman, J. (1988). Laddering theory, method, analysis, and interpretation. Journal of Advertising Research, 28(1), 11-31.

Romaniuk, J. (2003). Brand attributes - 'distribution outlets' in the mind. Journal of Marketing Communications, 9 , 73-92. doi:10.1080/1352726032000088896.

Schubert, F., Kandampully, J., Solnet, D., \& Kralj, A. (2010). Exploring Consumer Perceptions of Green Restaurants in the US. Tourism and Hospitality Research, 10(4), 286-300. doi:10.1057/thr.2010.17.

Woodruff, R. B. (1997). Customer value: The next source for competitive advantage. Journal of the Academy of Marketing Science, 25(2), 139-153. doi:10.1007/bf02894350.

Zhu, H., Wang, Q., Yan, L., \& Wu, G. (2009). Are consumers what they consume? - Linking lifestyle segmentation to product attributes: an exploratory study of the Chinese mobile phone market. Journal of Marketing Management, 25(3-4), 295-314. doi:10.1362/026725709X429764. 